\title{
Tissue Factor Expression in Colorectal Adenocarcinoma: Association with Angiogenesis and Clinical and Pathological Aspects
} \author{
Henrique Sarubbi Fillmann ${ }^{3}$ Gustavo Franco Carvalhal ${ }^{4(1)}$ \\ ${ }^{1} \mathrm{PhD}$ in Medicine and Health Sciences from PUC-RS and Professor in \\ the Department of Surgery at PUC-RS School of Medicine, Porto \\ Alegre, RS, Brazil \\ 2 Student of the Undergraduate Course in Medicine at PUC-RS, Porto \\ Alegre, RS, Brazil \\ 3 PhD from UFRGS and Professor at the School of Medicine at PUC-RS, \\ Professor at the Department of Surgery at the School of Medicine at \\ PUC-RS, Porto Alegre, RS, Brazil \\ ${ }^{4} \mathrm{PhD}$ in Urology from USP and Professor in the Department of Surgery \\ at the PUC-RS School of Medicine, Porto Alegre, RS, Brazil
}

Lúcio Sarubbi Fillmann ${ }^{10}$ Laura Pinho Fillmann ${ }^{20}$ Leonardo Zarpelon de Oliveira20

Address for correspondence Lúcio Sarubbi Fillmann, PhD, Avenida Ipiranga, 6690, sala 307, Centro Clínico PUC-RS, Porto Alegre, RS, 90610-000, Brazil (e-mail: Isfillmann@yahoo.com.br).

J Coloproctol 2022;42(1):54-58.

\begin{abstract}
Introduction Tissue factor (TF) expression has been described in various neoplasms and was correlated with angiogenesis and metastases.

Objectives To describe TF expression in colorectal cancers, correlating it with microvessel density and clinical and pathological variables.

Methods Immunohistochemistry was used to determine TF expression and microvessel density. The Student $t$-test was used to compare high and low TF expression with microvessel density and with age. The chi-squared test was used for other comparisons, and Kaplan-Meier curves were used for survival analyses.

Results Forty-three patients were operated with curative intent. Their mean age was $58.1 \pm 12.6$ years old, and $62.8 \%$ were male. The rectum was the most common

Keywords

- tissue factor

- angiogenesis

- colorectal adenocarcinoma location $(60,4 \%)$, and most tumors reached the serosa and peri-intestinal fat $(72.1 \%)$. Lymph nodes were positive in $46.5 \%$, and $72.1 \%$ of the tumors were moderately differentiated adenocarcinomas. Death occurred in $27.6 \pm 12.8$ months in $51.1 \%$ of the patients who had recurrence. Tissue factor expression was intense in $88.4 \%$. There was a positive correlation between TF expression and microvessel density $(p=0.02)$, and
\end{abstract}

The present study was performed at Colproctology Service of the Hospital São Lucas, Pontifícia Universidade Católica do Rio Grande do Sul, Porto Alegre, RS, Brazil. received

June 7, 2021

accepted after revision

September 6, 2021

published online

January 31,2022
DOI https://doi.org/

10.1055/s-0041-1739453.

ISSN 2237-9363.

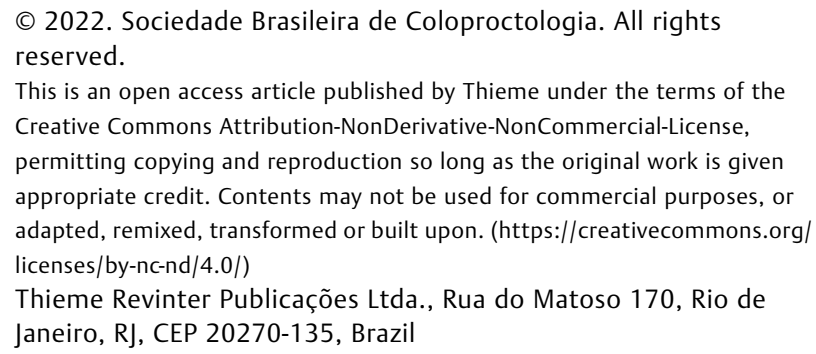

(c) 2022. Sociedade Brasileira de Coloproctologia. All rights reserved.

This is an open access article published by Thieme under the terms of the Creative Commons Attribution-NonDerivative-NonCommercial-License, permitting copying and reproduction so long as the original work is given appropriate credit. Contents may not be used for commercial purposes, or adapted, remixed, transformed or built upon. (https://creativecommons.org/ licenses/by-nc-nd/4.0/)

Thieme Revinter Publicações Ltda., Rua do Matoso 170, Rio de Janeiro, RJ, CEP 20270-135, Brazil 
between TF and older age $(p<0.01)$. There was no correlation between TF expression and other variables (gender, histological type, penetration into the intestinal wall, and lymphatic and systemic metastases). Tissue factor expression did not correlate with survival.

Conclusion Tissue factor expression correlated with increased microvessel density and older age. Further studies are necessary to ascertain the clinical relevance of TF in colorectal cancer.

\section{Introduction}

Pivotal studies published by the end of the $19^{\text {th }}$ century have shown that blood coagulation results from the interaction among prothrombin, calcium, fibrinogen, and a fourth factor known as thromboplastin or, more commonly, tissue factor (TF). ${ }^{1}$ Tissue factor acts in the coagulation cascade by combining with factor VII, a complex that has a proteolytic role, resulting in the activation of factors IX and X, and ultimately leading to the conversion of fibrinogen into fibrin, resulting in the final clot formation. ${ }^{1-3}$ The expression of TF was identified in various cell types from embryonal tissues, especially during developmental phases in which the coagulation factors are not present or are unable to cross the placental barrier. ${ }^{1}$ In addition, triggers to the induction of TF expression include inflammatory cytokines (such as tumor necrosis factor [TNF]), mitogens (such as vascular endothelial growth factor [VEGF], insulin, and fibroblast growth factor [FGF]), hormones, endotoxins, viral infections, hypoxia, and trauma. ${ }^{1}$

In addition to being associated with many hypercoagulability states, ${ }^{4,5}$ TF is related to cancer physiopathology due to its ability to enhance VEGF expression and to promote abnormal proliferation of blood vessels, which is fundamental to tumor development and to the metastatic process. ${ }^{4,6-8}$ Tissue factor expression is increased in many neoplasms, such as small cell lung cancers, ${ }^{9}$ gliomas, ${ }^{10}$ breast cancers, ${ }^{11}$ pancreatic cancers, ${ }^{12}$ colonic cancers, ${ }^{6}$ prostate cancers, ${ }^{13}$ and gastric cancers, ${ }^{14}$ being also related to more advanced stages of these tumors.

\section{Objective}

The goal of our study is to describe TF expression in colorectal adenocarcinomas, correlating the intensity of the expression with microvessel density. Additionally, we aim to correlate TF expression with variables such as age, gender, depth of tumor penetration into the intestinal wall, lymphatic metastases, location of the tumors in the intestine, sites of metastatic recurrence, histologic grade, and survival.

\section{Methods}

Our sample consisted of patients diagnosed with colorectal adenocarcinoma treated at the Department of Coloproctology of the Hospital São Lucas, Pontifícia Universidade Católica do Rio Grande do Sul, Porto Alegre, state of Rio Grande do
Sul, Brazil, with at least 5 years of follow-up since surgery. The 43 selected patients were submitted to exclusive intestinal resections according to therapeutic curative (nonpalliative) oncological criteria. We compared TF expression and microvessel density in paraffin-embedded tissues of the colorectal tumors. Clinical and pathological data collected were age and gender, location of the tumors in the rectum or colon, histological differentiation grade, depth of penetration into the intestinal wall, presence of lymph node metastases, and survival in months after surgery.

\section{Immunohistochemistry}

The tumors were fixed and embedded in paraffin, and subsequently submitted to $3 \mu \mathrm{m}$ cuts with antigen retrieval in $99 \%$ water bath for 30 minutes at $99^{\circ} \mathrm{C}$ using Tris/ethylenediamine tetraacetic acid (EDTA), pH 9 (20 mM Tris/0,65 mM EDTA). The blockage of endogenous peroxidase was performed with a $3 \%$ peridrol solution (H2O2 in methylic alcohol) for 30 minutes. The tissue was then immersed in a 5\% PBS buffered saline solution to control the background and incubated with mouse monoclonal antibody anti-TF 1 (1:30 dilution) and anti-human monoclonal mouse antibody for CD34 (1:400 dilution). Detection was performed with the Kit Dako LSAB + peroxidase, and sections were revealed with the chromogen 3,3' - diaminoazobenzidine in a solution with PBS and $0.002 \%$ hydrogen peroxide, contracolored with hematoxylin. Finally, the samples were dehydrated, clarified, and mounted in slides and covers.

\section{Tissue Factor Expression}

Cut sections of the tumors were prepared according to immunohistochemistry methods, using an anti-TF monoclonal antibody. The samples were analyzed under 100x magnification by 2 trained observers to determine the percentage of malignant cells positive to the antigen. The tumors were divided into 4 groups according to TF expression: $1(0-25 \%$ of the cancer cells stained), 2 (26-50\% of the cancer cells stained), 3 (51-75\% of the cancer cells stained), and 4 (76-100\% of the cancer cells stained) (-Fig. 1).

\section{Microvessel density}

We used immunohistochemistry techniques with an antiendothelial CD34 antibody, which stained micro vessels with a brownish color, contrasting with the light blue background (hematoxylin). After identifying areas of greater vascularization (hot spots) in 100x magnification, images were captured in 20 different fields to proceed to microvessel 

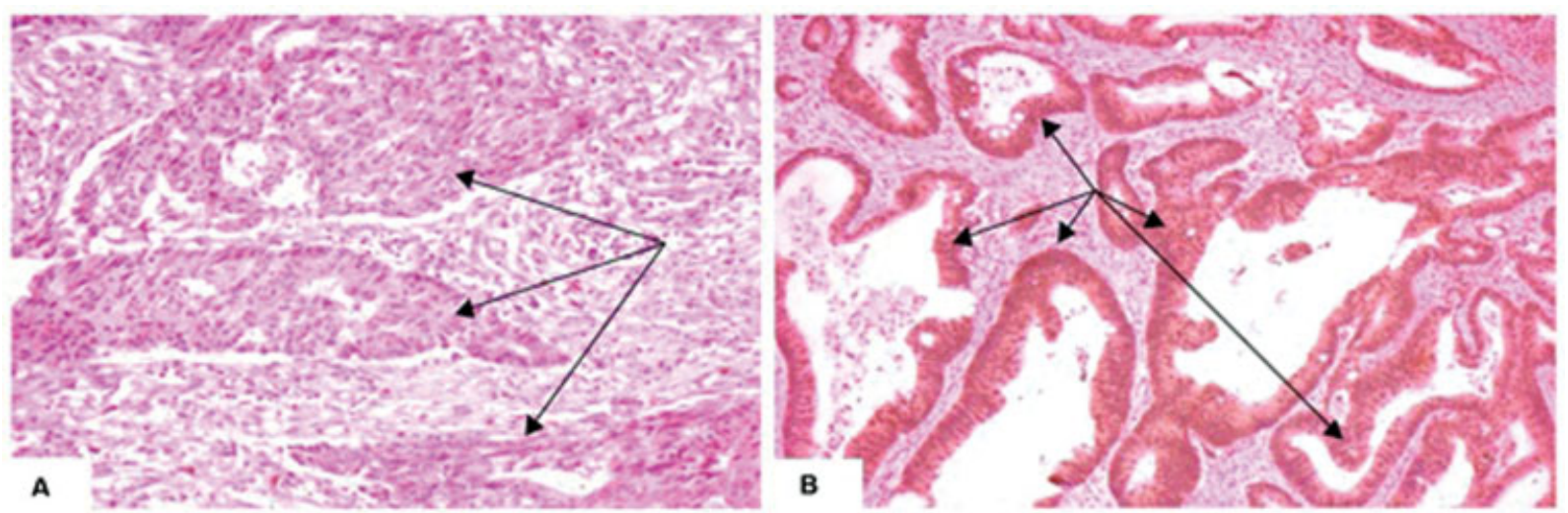

Fig. 1 Examples of tissue factor expression in two of our samples. (A) absence of tissue factor expression in cells of adenocarcinoma glands (indicated by arrows). (B) Tissue factor expression in 100\% of the cells of glands from a colorectal adenocarcinoma (arrows point to neoplastic cells intensely expressing tissue factor).

counting in 400x magnification. We included in the counting isolated blood vessel cells as well as larger blood vessels without muscle layers and adventitia, without necessarily including the visualization of the vessel lumen or the presence of red blood cells to consider it a vessel. Counting was made after inserting a correction grid following an ordinal scale. An arithmetic mean of the 20 selected fields was then produced for each tumor.

\section{Statistical Analysis and Ethics}

Categorical data were described through frequency and percentage, whereas quantitative data were described through mean and standard deviation (SD). The Student $t$ test was used to compare age and microvessel density between groups of low and high TF expression. The remaining variables were compared for low and high TF expression with the chi-squared test. For survival analysis, KaplanMeier curves were produced. The present study was authorized by the Ethics and Research Committee of our institution (documents 174/04-PG and 606/04-CEP).

\section{Results}

\section{Patients and Samples Characteristics}

The mean age of the patients was $58.1 \pm 12.6$ years old, with a predominance of the male gender (62.8\%). The rectum was the most common location of the tumors (60.4\%), with most tumors extending to the serosa and to peritumoral fat (72.1\%). Regional lymph nodes were positive for tumors in $46.5 \%$ of the patients, and $72.1 \%$ of the tumors were classified as moderately differentiated adenocarcinomas. Tumor recurrence occurred in $51.1 \%$ of the patients, with an overall survival of $27.6 \pm 12.8$ months after surgery with the liver being the most common metastatic site (50\%). Patients who did not have recurrence were followed-up for $103.8 \pm 34.5$ months.

\section{Tissue Factor Expression}

Tumors that expressed TF intensely (76-100\% of tumor cells positive for TF, group 4 ) were present in $88.4 \%$ of the patients; $7 \%$ of the patients presented with group 1 tumors $(0-25 \%$ of tumor cells expressing TF), and $4.6 \%$ of the patients presented with group 2 tumors (26-50\% of tumor cells expressing TF). There were no patients with group 3 tumors (51-75\% of cells positive for TF). For the statistical analysis, we considered two groups: high expression of TF (group 4) and low expression of TF (groups 1 and 2, encompassing lesions with $0-50 \%$ of tumor cells stained for TF).

\section{Correlation between Tissue Factor Expression and Microvessel Density}

Tumors with high expression of TF (group 4) revealed and average of $28.4 \pm 10.1$ microvessels by $400 \mathrm{x}$ microscopy field, whereas lesions with low TF expression (groups 1 and 2) showed an average of $17.1 \pm 7.9$ micro vessels per $400 \mathrm{x}$ microscopy field. High TF expression correlated positively with an increased microvessel density in our sample $(p=0.022)$ (-Fig. 2).

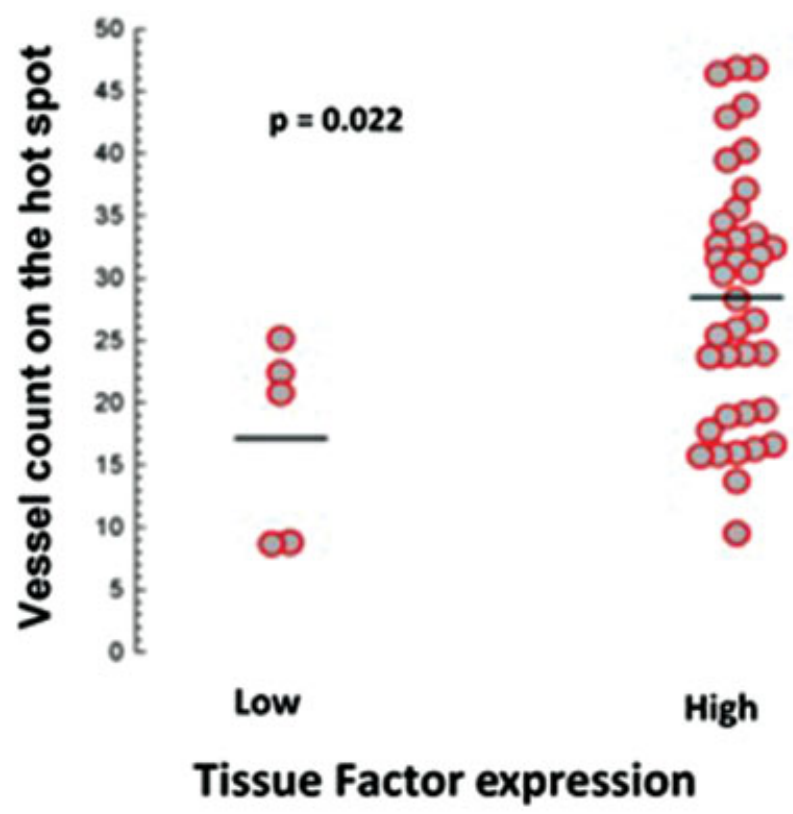

Fig. 2 Graphic representation of microvessel density according to tissue factor expression. 


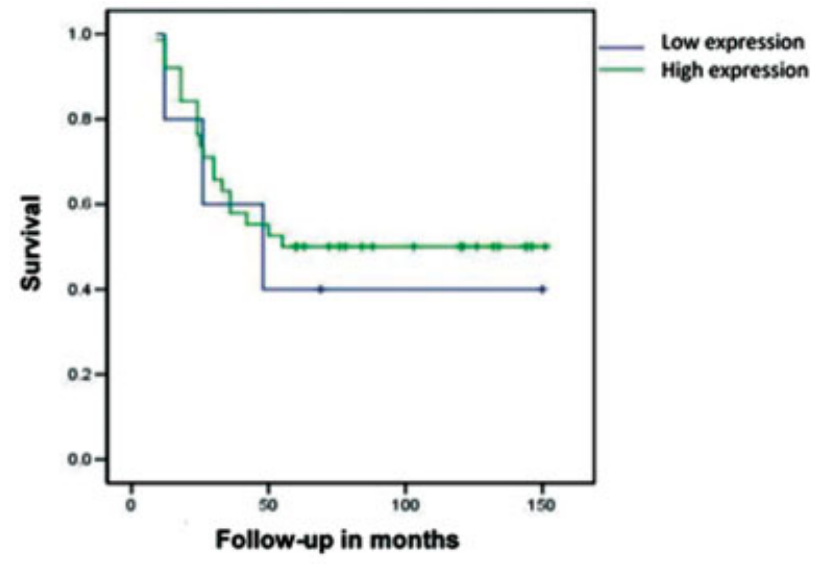

Fig. 3 Kaplan-Meier survival curves of patients with low and high tissue factor expression $(p=N S)$.

\section{Correlation between TF expression and clinical and pathological variables}

The mean age of the patients in the high TF expression group was $60.2 \pm 11.5$ years old, whereas the mean age of the patients in the low TF expression group was $42.6 \pm 10.2$ years old. The difference was statistically significant $(p<0.01)$. There were no statistically significant differences between TF expression and gender, histologic grade, depth of tumor penetration into the intestinal wall, regional lymph node involvement, and survival (- Fig. 3).

- Table 1 summarizes the correlation between low or high TF expression and other clinical and pathological variables evaluated.

\section{Discussion}

Interactions between coagulation and cancer have been studied for a long time. Possible mechanisms may include ${ }^{15}$ : direct activation of the coagulation cascade by circulating tumor cells in the blood stream, possibly related to the hypercoagulable states observed in patients with cancer
(Trousseau syndrome), extravascular activation of coagulation factors in malignant tumors, and the induction of coagulation-related factors by inflammatory cells recruited by the host in response to the tumor.

Our findings of an elevated TF expression in colorectal cancers suggest its importance in the study of these tumors. In our sample, $88.3 \%$ of the cases revealed a high TF expression in cancer cells. Therefore, TF could also interact with other significant elements associated with colorectal cancer progression. We have also shown that, in colorectal cancer, TF is associated with tumor angiogenesis, since lesions with high TF expression revealed an increased microvessel density. In colorectal cancer, Seto et al. ${ }^{16}$ acknowledged an important prognostic role for TF but could not find a statistically significant association between TF and the expression of VEGF. These authors suggested that other agents associated with the presence of TF might be responsible for the metastatic spread of colorectal cancer.

The statistically significant association between TF expression and microvessel density observed in our study suggests a proangiogenic stimulus associated with the presence of TF in colorectal cancer. However, despite finding a positive correlation between TF and angiogenesis, we did not find any effect on prognosis and survival. In the literature, there is much controversy regarding the prognostic importance of microvessel density. ${ }^{17-24}$ However, tumor angiogenesis and the resulting metastatic process are multifactorial events that depend upon a strict balance between pro and antiangiogenic factors. ${ }^{25}$ These mechanisms need to be studied in larger patient cohorts to enhance our comprehension of the actual interactions between coagulation, tumor angiogenesis, and disease progression in colorectal cancer.

Finally, excluding microvessel density, age was the only clinical or pathological variable statistically associated with TF expression in our cohort. The group of patients with low TF expression was significantly younger than the group of patients with high TF expression. Seto et al. ${ }^{16}$ also observed

Table 1 Characteristics of colorectal cancer patients according to tissue factor expression

\begin{tabular}{|l|l|l|l|}
\hline & \multicolumn{2}{|l|}{ Tissue factor expression } & \\
\hline & Low & High & p-value \\
\hline Features & $\mathbf{n = 5}$ & $\mathbf{n}=\mathbf{8}$ & 1.00 \\
\hline Male gender, $n(\%)$ & $3(60.0)$ & $24(63.2)$ & $<0.01$ \\
\hline Age, years old & $42.6 \pm 10.2$ & $60.2 \pm 11.5$ & \\
\hline Histological type, $n$ (\%) & & & \\
\hline Well-differentiated & $0(0.0)$ & $2(5.3)$ & \\
\hline Moderately differentiated & $3(60.0)$ & $28(73.7)$ & \\
\hline Poorly differentiated & $2(40.0)$ & $8(21.0)$ & 1.00 \\
\hline Extensive wall penetration, $n(\%)$ & $4(80.0)$ & $30(78.9)$ & 0.65 \\
\hline Lymph nodes metastases, $n(\%)$ & $3(60.0)$ & $17(44.7)$ & 1.00 \\
\hline Systemic metastasis, $n(\%)$ & $3(60.0)$ & $19(50.0)$ & 0.02 \\
\hline Microvascular density, vessels/field & $17.1 \pm 7.9$ & $28.4 \pm 10.1$ & \\
\hline
\end{tabular}


that, in their series, patients with low TF expression were younger, although the difference was not statistically significant. We believe that this association should be further explored in other series.

Regarding future studies, as suggested by others, ${ }^{16}$ analyzing the interactions between VEGF, increased angiogenesis, and TF/FVIIa, we could better understand the disease progression mechanisms in colorectal cancer. ${ }^{26}$ In tumors with increased TF expression and activity, the prevention of thromboembolic events could impact mortality. ${ }^{6}$ It is also known that infection in the postoperative setting may result in an increase in TF production and in greater risks of thrombosis and thromboembolism, ${ }^{27}$ a considerable problem in colorectal cancer. Tissue factor could also be of use in cancer diagnosis and follow-up. Increased urinary levels of $\mathrm{TF}$ have been identified in patients with breast and colon cancer, also correlating with tumor grade in these tumors. ${ }^{28}$ Lastly, we should consider the potential therapeutic role of blockers of the coagulation cascade such as tinzaparin, a lowmolecular weight heparin that activates intracellularly an inhibitor of the TF pathway. ${ }^{29}$

\section{Conclusion}

Tissue factor is highly expressed in the membrane and cytoplasm of cells in most colorectal adenocarcinomas, and its expression positively correlates with increased microvessel density and older age. Further studies are needed to ascertain the role of TF as a prognostic factor or therapeutic target in colorectal cancer.

\section{Conflict of Interests}

The authors have no conflict of interests to declare.

\section{References}

1 Carmeliet P, Collen D. Tissue factor. Int J Biochem Cell Biol 1998;30 (06):661-667

2 Banner DW. The factor VIIa/tissue factor complex. Thromb Haemost 1997;78(01):512-515

3 Higashi S, Iwanaga S. Molecular interaction between factor VII and tissue factor. Int J Hematol 1998;67(03):229-241

4 Rickles FR, Patierno S, Fernandez PM. Tissue factor, thrombin, and cancer. Chest 2003;124(03):58S-68S

5 Goad KE, Gralnick HR. Coagulation disorders in cancer. Hematol Oncol Clin North Am 1996;10(02):457-484

6 Lykke J, Nielsen HJ. The role of tissue factor in colorectal cancer. Eur J Surg Oncol 2003;29(05):417-422

7 Folkman J. Tumor angiogenesis and tissue factor. Nat Med 1996;2 (02):167-168

8 Zhang J, Ding J, Zhang X, Shao X, Hao Z. Regulation of vascular endothelial growth factor (VEGF) production and angiogenesis by tissue Factor (TF) in SGC-7901 gastric cancer cells. Cancer Biol Ther 2005;4(07):769-772

9 Sawada M, Miyake S, Ohdama S, et al. Expression of tissue factor in non-small-cell lung cancers and its relationship to metastasis. $\mathrm{Br} J$ Cancer 1999;79(3-4):472-477
10 Guan M, Jin J, Su B, Liu WW, Lu Y. Tissue factor expression and angiogenesis in human glioma. Clin Biochem 2002;35(04): 321-325

11 Ueno T, Toi M, Koike M, Nakamura S, Tominaga T. Tissue factor expression in breast cancer tissues: its correlation with prognosis and plasma concentration. Br J Cancer 2000;83(02):164-170

12 Ueda C, Hirohata Y, Kihara Y, et al. Pancreatic cancer complicated by disseminated intravascular coagulation associated with production of tissue factor. J Gastroenterol 2001;36(12):848-850

13 Abdulkadir SA, Carvalhal GF, Kaleem Z, et al. Tissue factor expression and angiogenesis in human prostate carcinoma. Hum Pathol 2000;31(04):443-447

14 Toneto MG, Depaula PL, Debon L, et al. Immunohistochemical analysis of tissue factor expression in gastric carcinoma: correlations with prognosis and survival. Análise da expressão imunohistoquímica do fator tecidual no carcinoma gástrico: correlações com prognóstico e sobrevida. Rev Col Bras Cir. 2018;45(06):e2030. Published 2018 Nov 29. Doi: 10.1590/0100-6991e-20182030

15 Shoji M, Hancock WW, Abe K, et al. Activation of coagulation and angiogenesis in cancer: immunohistochemical localization in situ of clotting proteins and vascular endothelial growth factor in human cancer. Am J Pathol 1998;152(02):399-411

16 Seto S, Onodera $\mathrm{H}$, Kaido T, et al. Tissue factor expression in human colorectal carcinoma: correlation with hepatic metastasis and impact on prognosis. Cancer 2000;88(02):295-301

17 Frank RE, Saclarides TJ, Leurgans S, Speziale NJ, Drab EA, Rubin DB. Tumor angiogenesis as a predictor of recurrence and survival in patients with node-negative colon cancer. Ann Surg 1995;222 (06):695-699

18 Tanigawa N, Amaya $\mathrm{H}$, Matsumura $\mathrm{M}$, et al. Tumor angiogenesis and mode of metastasis in patients with colorectal cancer. Cancer Res 1997;57(06):1043-1046

19 Kaio E, Tanaka S, Kitadai Y, et al. Clinical significance of angiogenic factor expression at the deepest invasive site of advanced colorectal carcinoma. Oncology 2003;64(01):61-73

20 Tarta C. Análise digital de imagem e estereologia da angiogênese em adenomas e no carcinoma colorretal invasivo de submucosa (tese). Porto Alegre: Faculdade de Medicina da Universidade Federal do Rio Grande do Sul; 2003

21 Banner BF, Whitehouse R, Baker SP, Swanson RS. Tumor angiogenesis in stage II colorectal carcinoma: association with survival. Am J Clin Pathol 1998;109(06):733-737

22 Lindmark G, Gerdin B, Sundberg C, Påhlman L, Bergström R, Glimelius B. Prognostic significance of the microvascular count in colorectal cancer. J Clin Oncol 1996;14(02):461-466

23 Cianchi F, Palomba A, Messerini L, et al. Tumor angiogenesis in lymph node-negative rectal cancer: correlation with clinicopathological parameters and prognosis. Ann Surg Oncol 2002;9(01):20-26

24 Abdalla SA, Behzad F, Bsharah S, et al. Prognostic relevance of microvessel density in colorectal tumours. Oncol Rep 1999;6(04): 839-842

25 Chung YS, Maeda K, Sowa M. Prognostic value of angiogenesis in gastro-intestinal tumours. Eur J Cancer 1996;32A(14):2501-2505

26 Siegbahn A. Cellular consequences upon factor VIla binding to tissue factor. Haemostasis 2000;30(Suppl 2):41-47

27 Lwaleed BA, Bass PS, Cooper AJ. The biology and tumour-related properties of monocyte tissue factor. J Pathol 2001;193(01):3-12

28 Lwaleed BA, Chisholm M, Francis JL. Urinary tissue factor levels in patients with breast and colorectal cancer. J Pathol 1999;187(03): 291-294

29 Mousa SA, Mohamed S. Anti-angiogenic mechanisms and efficacy of the low molecular weight heparin, tinzaparin: anti-cancer efficacy. Oncol Rep 2004;12(04):683-688 